\title{
SURFACE CHARACTERISTICS COMPARISON BETWEEN TRADITIONAL AND ONE STEP PRODUCTION CYCLE
}

\author{
Sevil DEMIRCí ${ }^{1 *}$, Semih ERTÜRK $^{2}$, Ŭgur ÜZEL ${ }^{3}$ \\ Tofaş Türk Otomobil Fabrikası A.Ş., R\&D Material Engineering Department, Bursa, Türkiye
}

\begin{abstract}
Surface quality behaviour was investigated for one step production system compared to traditional painting process. This study was conducted to compare and analyse the effect of one step production cycle on surface quality when compared with traditional production system. Sample plates were prepared by traditional painting process with acrylic solvent-based paint and one step production cycle with polyurethane (PU) coating systems. Surface quality of plates were analysed regarding scratch resistance, thermal aging resistance and orange peeling formation. Test methods were determined according to Fiat painted plastic part qualification norms. Test results revealed that gloss loss, roughness values and orange peeling formation affinity were less for one step production system with PU than conventional system with solvent based acrylic paint. This study contributes to revealing surface quality performance for the methods of producing painted parts that are more resistant to scratch, thermal conditions and having much fewer surface defects like orange peeling.
\end{abstract}

Keywords: Surface defects for painted parts, production systems for painted parts

* sevil.demirci@tofas.com.tr, https://orcid.org/0000-0002-3555-4607 


\section{GELENEKSEL VE BİR ADIMDA ÜRETIM PROSESİ ARASINDAKİ YÜZEY ÖZELLIKLERININ KARŞILAŞTIRMASI}

\section{Özet}

Geleneksel boyama işlemine ile bir basamaklı üretim sistemi arasındaki yüzey kalitesi davranış1 incelenmiştir. $\mathrm{Bu}$ çalışma, geleneksel üretim sistemine göre bir kademeli üretim döngüsünün yüzey kalitesi üzerindeki etkisini karşılaştırmak ve analiz etmek için yapılmıştır. Numune plakaları akrilik solvent bazlı boya ile geleneksel boyama işlemi ve poliüretan (PU) kaplama sistemleri ile bir aşamalı üretim döngüsü ile hazırlanmıştır. Plakaların yüzey kalitesi çizilme direnci, 1sıl yaşlanma direnci ve portakallanma oluşumu açısından analiz edilmiştir. Test yöntemleri Fiat boyalı plastik parça yeterlilik normlarına göre belirlenmiştir. Test sonuçları, PU ile bir aşamalı üretim sisteminin parlaklık kaybı, pürüzlülük değerleri ve portakallanma oluşum yatkınlığının solvent bazlı akrilik boya içeren geleneksel sisteme göre daha az olduğunu ortaya koymuştur. Bu çalışma, çizilmeye, ısıl koşullara daha dayanıklı olan ve portakallanma gibi daha az yüzey kusuruna sahip boyalı parçaların üretilme yöntemleri için yüzey kalitesi performansının ortaya çıkmasına katkıda bulunmaktadır.

Anahtar Kelimeler: Boyalı parçalar için yüzey hataları, boyalı parçalar için üretim sistemleri

\section{INTRODUCTION}

Plastic parts are painted to protect the parts from environmental conditions and influence customer's perception. In traditional painting cycle plastic painted parts are produced by painting with primer, basecoat and, if necessary, individual varnish layers as shown on Figure 1 schematically. This process is carried out by manual or automatic robotic painting systems. In conventional application technology, the plastic materials are sent to the paint shop after the injection process is completed and proceeds in the painting operations of the separate layers. There are intermediate painting lines and ovens more than one. This process is one of the most energy consumptive step among whole process including beginning from the part injection to assembly. In this process, time, material, labour and quality losses are experienced in every operation step. The visual quality of the painted parts varies depending on the application parameters of each operation. The part is open to external influences. Dust and similar problems cause increase of scrap ratio. Because of that reasons and demand of high surface quality for the 
parts, new technologies for coating the parts are developed such as colored raw material injection and film applications. Coloured raw material injection technology provides eliminating painting process, but colour alternative is limited for this technology. Film applications technologies are also basic processes when compared the conventional painting, but films are not so robust for external trims.

Combining injection and painting in one cycle, in-mould painting is one of these new developing coating technologies. Painting in the mould technology can perform both injection and painting processes in the mould simultaneously. One step process combines injection moulding and painting, which are separate operations in the conventional technique as it can be seen from Figure 2. This process allows to create injection moulded parts with a high-gloss hard-paint finish, refined depth effects or haptically impressive structured surfaces in a one step. Cycle time is less than the conventional method for both injection and painting process. This process has more production efficiency by providing less indirect labour and less scrap ratio. Also, it provides standard paint thickness and it prevents surface quality problems like as orange peeling and visual defects There are companies that developed technology of injection and painting in one mould combination and currently an automotive part is on a vehicle that was produced by this PU systems. The developers such as Krauss Maffei and automotive supplier Weidmann Plastics Technology studied joined a partnership to integrate the painting process in the injection mould with their other partners that are Hofmann Tool Manufacturing, Panadur and Bayer [1-2]. Similarly, Engel Austria GmbH presented a process called Decojet providing to transfer layer of paint and graining at the same time. This technology helps to add surface structures and haptical features to the colour and pattern [3].

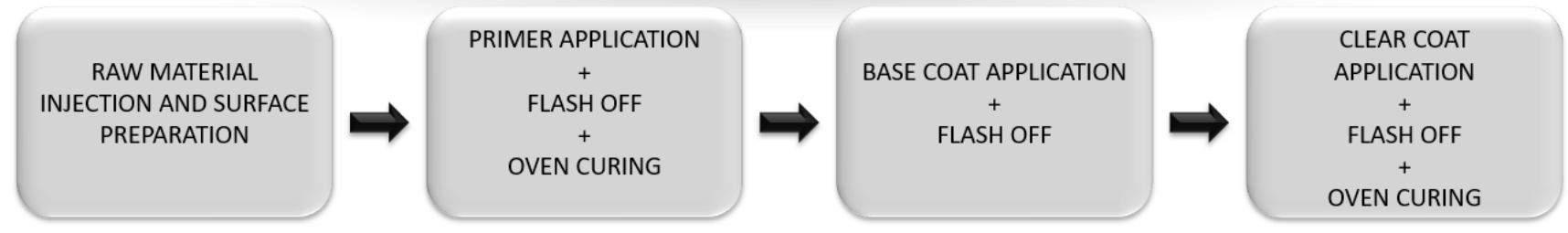

Figure 1: Schematic representation of traditional painting process with acrylic paint 


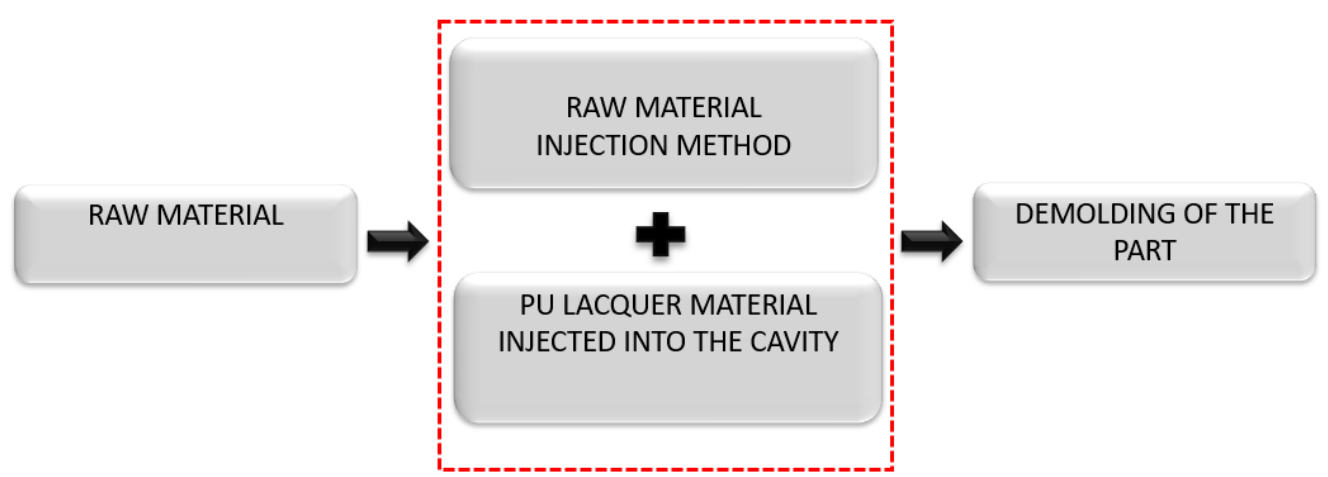

Figure 2: Schematic representation of one step production cycle with PU coating systems

Plastic part painting is an important process for surfaces having qualified and aesthetically good appearance regarding knowledge of painting process parameters and materials. It has known that painting technologies are being improved to decrease labour and material losses and increase surface quality and process yield. It is important to verify performance of new materials and painting technologies to reveal the feasibility. The surface quality of one step painting system with polyurethane systems was investigated in this paper.

\section{MATERIAL AND METHODS}

Plates that were produced with traditional system with solvent based acrylic paint are having three coating separate layers: Primer, basecoat and acrylic clear coat. The colour of the plates is piano black. The plates were painted in a paint shop.

Plates that were produced with one step production having one coating layer: Polyurethane casting lacquer from Votteler (PU911RK-PURIFLOW systems) with Engel 500 injection machine with a Hennecke PU mixing head.

Surface quality comparison was made by investigating performances after scratch resistance (ISO 20566: Paints and varnishes, determination of the scratch resistance of a coating system using a laboratory-scale car-wash), thermal aging resistance (Fiat Internal Standard LP-463PB-22-01: Cycle testing of painted surfaces) and orange peeling formation behaviour via Wave-Scan equipment.

These plates are not from the real parts. They were produced only to see scratch and visual quality performance regarding acrylic and PU systems with different painting systems. 


\subsection{Scratch Resistance Analysis}

Scratch resistance performance of the plates were investigated by a laboratory scale car wash instrument in the scope of method ISO 20566. Machine based washing is simulated in the laboratory environment using a rotating polyethylene washing brush and silica powder solution consisting of $(1,50 \pm 0,05) \mathrm{g}$ of silica powder ( silica micro-powder having a mean particle size of $24 \mu \mathrm{m})$ per liter of tap water. The test conditions have been designed to be like real conditions moreover it can be more aggressive than the real conditions in a car wash. Scratch resistance performance was evaluated by two measurements which are gloss loss and roughness measurement. Gloss loss measurement was performed with Erichsen Picogloss 562 MC and roughness measurement was performed with Bruker Alicona Infinite Focus to analyse surface topography after the test.

In principle, gloss of a surface is measured by its reflection property and gloss scale depends on the angle at which surface is viewed as shown on Figure 3. Light is sent at a specific angle and reflection is quantified. $20^{\circ}$ is a more sensitive angle to haze effects of a high gloss surfaces [4]; therefore, gloss measurements were performed at the $20^{\circ}$ angle.

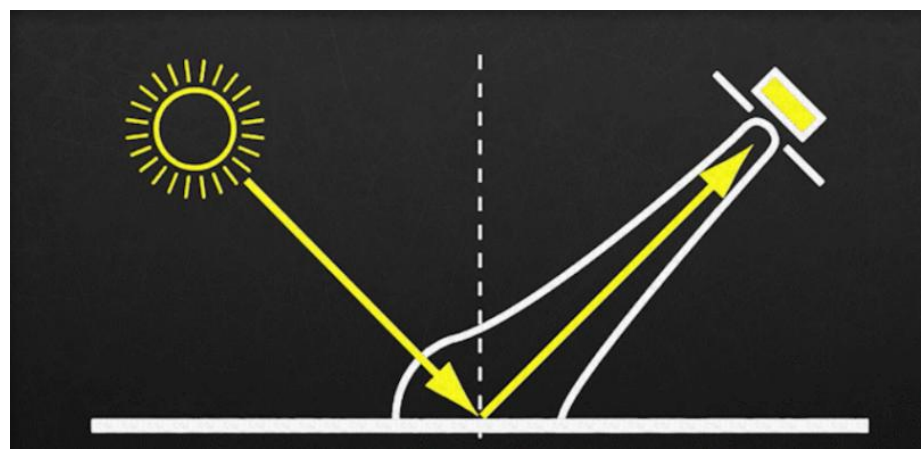

Figure 3: Schematic representation of gloss measurement mechanism

Surface topography can be described by three main parameters which are P-profile (overall profile), W-profile (waviness profile) and R-profile (surface roughness profile). The R-profile is calculated by using a cut-off filter to remove the longwave components from the P-profile. The $\mathrm{R}$-profile is therefore an intentional modification of the P-profile. $\mathrm{Ra}$ is the most common parameter in R-profile, and it is a mean value of all deviations from a straight line within the evaluation length, irrespective of the vertical direction so it cannot be determined whether the 
deviations are peaks or valleys.

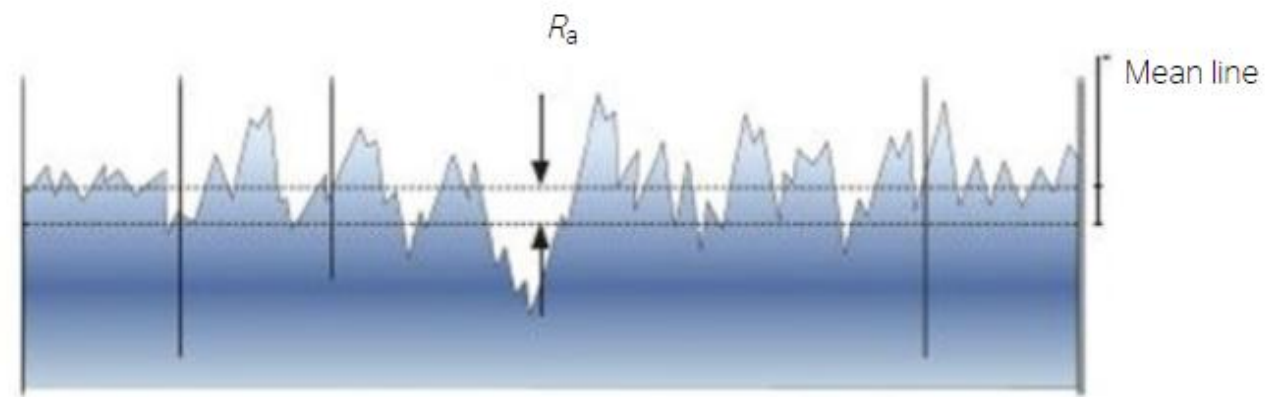

Figure 4: Graphical representation of $\mathrm{Ra}$

$\mathrm{Rz}$ is maximum profile height that is mean value of the individual profile heights obtained between the largest peak height and the largest valley depth within the evaluation length.

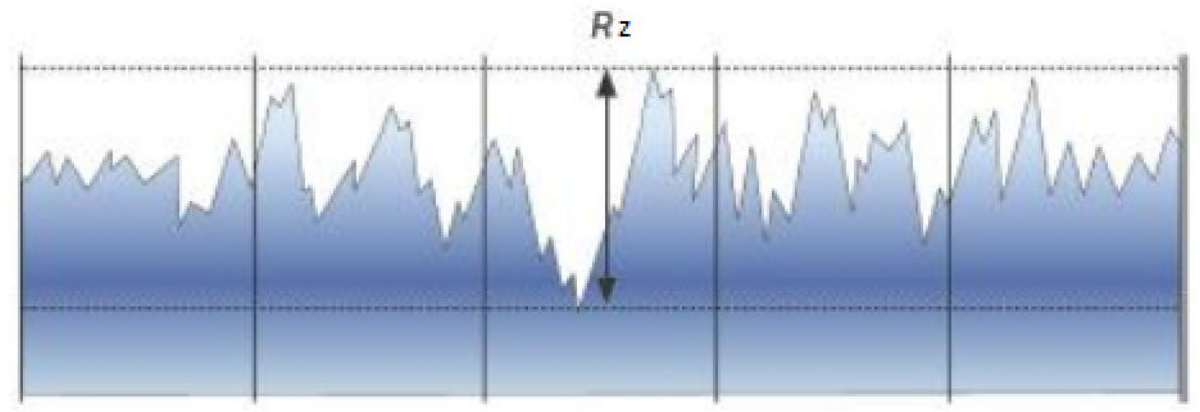

Figure 5: Graphical representation of $\mathrm{Rz}$

Rt is the arithmetic average of the height of the largest profile peak height and the largest profile valley depth within the evaluation length.

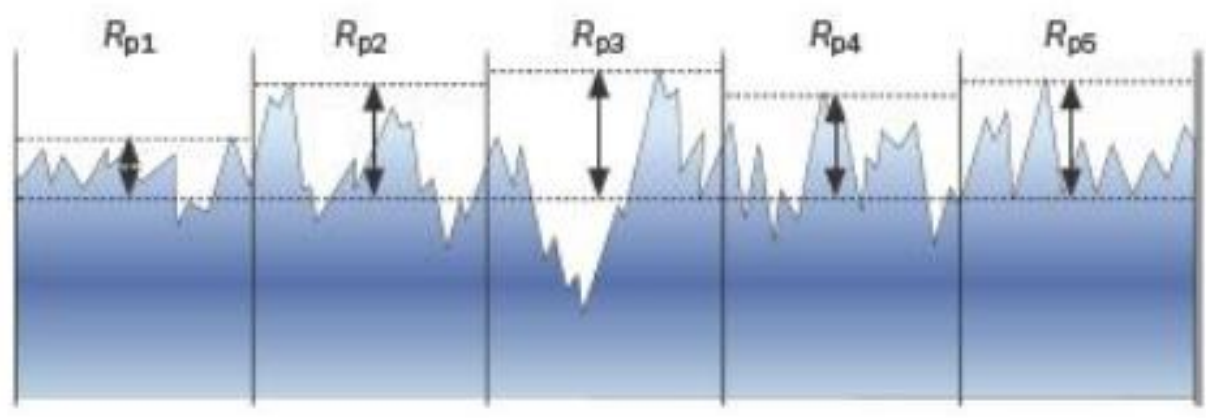

Figure 6: Graphical representation of Rt

These main surface roughness parameters are included in ISO 4287. These three parameters will provide an information regarding surface characteristics. 


\subsection{Thermal Aging Resistance}

Thermal aging resistance test is performed to find out defective area of the coating blistering, checking, cracking, loss of adhesion, colour and gloss. Total test cycle is 15 for exterior trim parts and this thermal cycle was performed considering exterior conditions. Every test loop includes specific defined time in hot oven at $80^{\circ} \mathrm{C}$, in the humidity cabinet at $40{ }^{\circ} \mathrm{C}$ with $95 \%$ $\mathrm{RH}$, in the cold box at $-30{ }^{\circ} \mathrm{C}$ and final conditioning at room temperature based on the Fiat Internal Standard LP-463PB-22-01 (Cycle testing of painted surfaces). These cycles were simulated by Weiss Thermal Cabinet (WK3-340/70). Visual defects were observed by naked eye and gloss losses of the plates were measured by Erichsen Picogloss $562 \mathrm{MC}$.

\subsection{Orange Peeling Formation Behaviour Comparison}

Orange peeling is a visual defect on the coated surfaces and this defect was determined by a Wave Scan instrument. The light from a laser strikes the surface and reflects into the photosensor in the device. The perfect surface without orange peel reflects the light back into the sensor directly without distortion. The device is rolled across the surface and measures point by point optical profile of the surface across a defined distance. The device analyses the structures according to their size. In order to simulate the human eye's resolution at various distances, the measurement signal is divided into several ranges using mathematical filter functions as shown in Figure 7. Measurement signal is divided into several ranges as in Table 1.

Table 1: Wave Scan Device Measurement Ranges

\begin{tabular}{|l|}
\hline Wa 0.1-0.3 mm wavelength \\
\hline Wb 0.3-1 mm wavelength \\
\hline Wc 1-3 mm wavelength \\
\hline Wd 3-10 mm wavelength \\
\hline We 10-30 mm wavelength \\
\hline SW 0.3-1.2 mm wavelength \\
\hline LW 1.2-12 $\mathrm{mm}$ wavelength \\
\hline
\end{tabular}




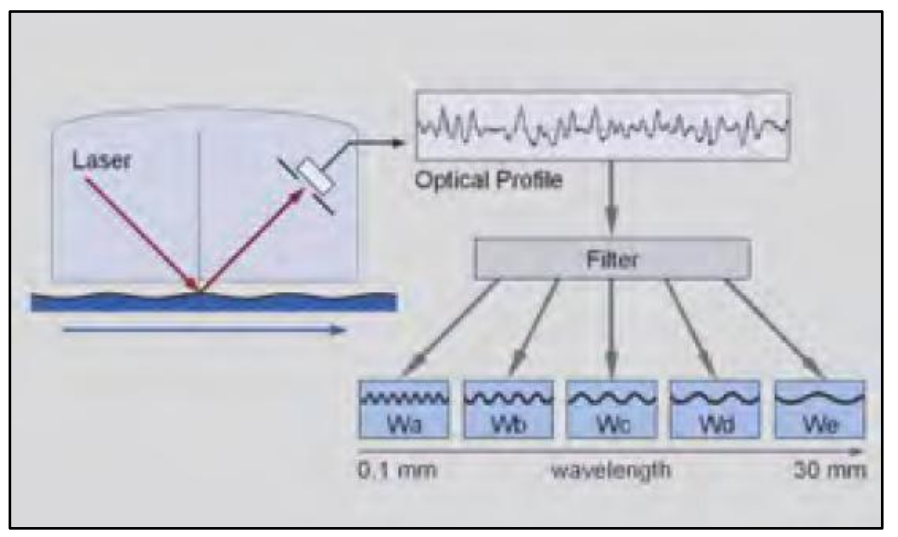

Figure 7: Wave-Scan equipment measurement in the range of different wavelengths

Ideally, the laser should reflect in the perfect mirror direction off the paint causing it to be directly bounced into the center of the photometer in the instrument. If orange peel is seen, then laser will be distorted by shorter wavelength (SW) or shifted by longer wavelength (LW) that is away from the center of the photometer. Structures with a size of 10 to $30 \mathrm{~mm}$ can best be seen at approximately $3 \mathrm{~m}$. Fine structures in a range of 0.1 to $1 \mathrm{~mm}$ can only be recognized at a close distance.

Also, the device gives the distinctness of reflected image (DOI) value as a result. This value is a quantification of the spread of light reflected at the specular angle. This is very important indicator that is showing image quality. High DOI shows us light is perfectly reflected. 


\section{RESULTS AND DISCUSSION}

\subsection{Scratch Resistance Analysis}

Gloss loss and roughness measurement were performed on the sample plates after the scratch resistance test. Visual images of the plates are shown after the test on the Figure 8.

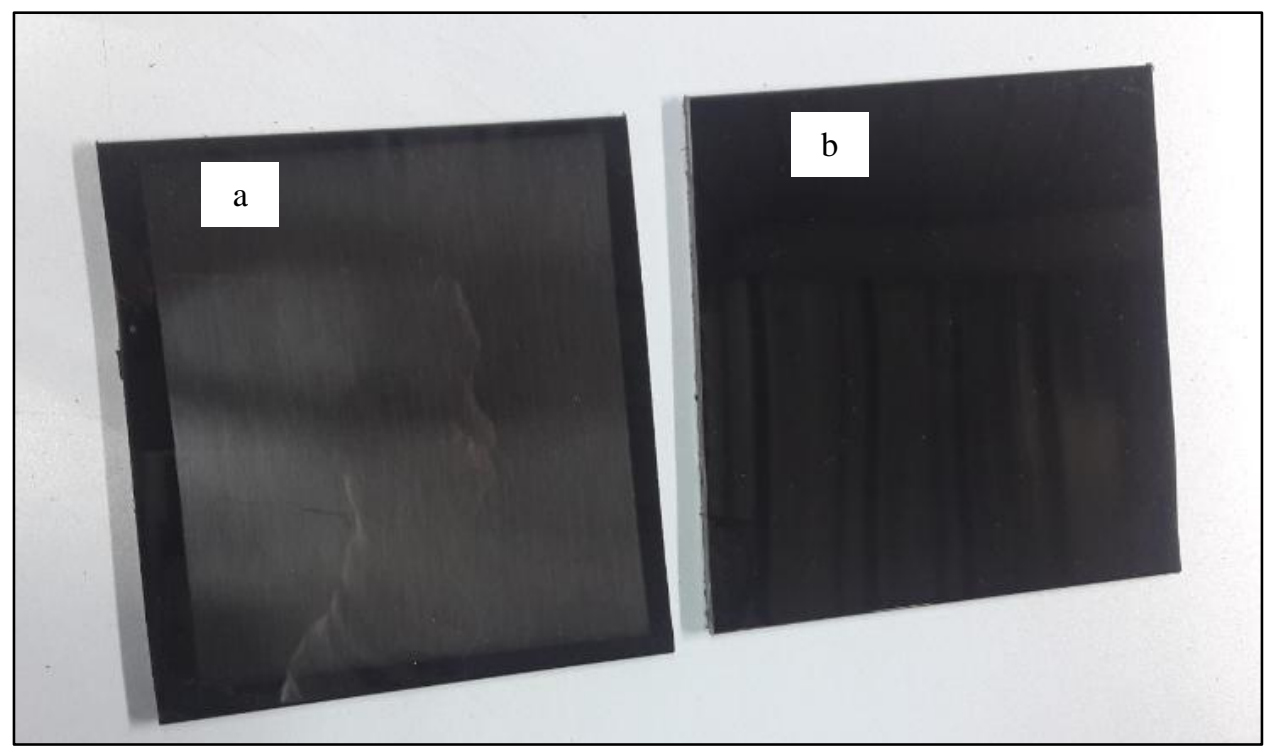

Figure 8: Image of a) conventional paint system with acrylic paint and

b) one step production systems with polyurethane lacquer after test

Figure 8 represents conventional system with solvent based acrylic paint and one step production system with polyurethane lacquer differ from each other regarding intensity of scratches after the test. Conventional paint system sample exhibited much scratches after the test compared to one step system.

Gloss losses for both type plates were measured and summarized in the Table 2. Results indicated that gloss loss is 1,2 times higher for conventional paint system when compared with the one step system.

Table 2: Gloss loss values after scratch test

\begin{tabular}{|l|l|}
\hline Paint System & Gloss Loss $\left(20^{\mathbf{}}\right.$ ) \\
\hline Conventional with solvent based acrylic paint & 46.5 \\
\hline One step with polyurethane lacquer & 40.5 \\
\hline
\end{tabular}


Surface roughness results are summarized as $\mathrm{Ra}, \mathrm{Rz}$ and $\mathrm{Rt}$ values in the Table 3. Ra value which is the main parameter for surface roughness evaluation defining mean of all deviations is $13 \%$ higher for conventional than one step system. Additionally, $\mathrm{Rz}$ value which is the largest peak height and the largest valley depth is resulted much more for conventional system when compared one step system.

Table 3: Roughness profile parameters after the scratch test

\begin{tabular}{|l|c|c|}
\cline { 2 - 3 } \multicolumn{1}{c|}{} & \multicolumn{2}{c|}{ Paint System } \\
\hline Ra/Mean roughness of the profile & $\begin{array}{c}\text { Conventional system } \\
(\mu \mathrm{m})\end{array}$ & $\begin{array}{c}\text { One step system } \\
(\mu \mathrm{m})\end{array}$ \\
\hline Rz/Maximum profile height average & 0.571 & 0.504 \\
\hline Rt/Total profile height & 4.996 & 4.762 \\
\hline
\end{tabular}

\subsection{Thermal Aging Resistance Test}

Thermal aging test performed to see how surface quality was affected for conventional system with acrylic paint and one step production system with polyurethane lacquer comparatively. The visual images are on the Figure 9 to evaluate the existence of any visual defects.

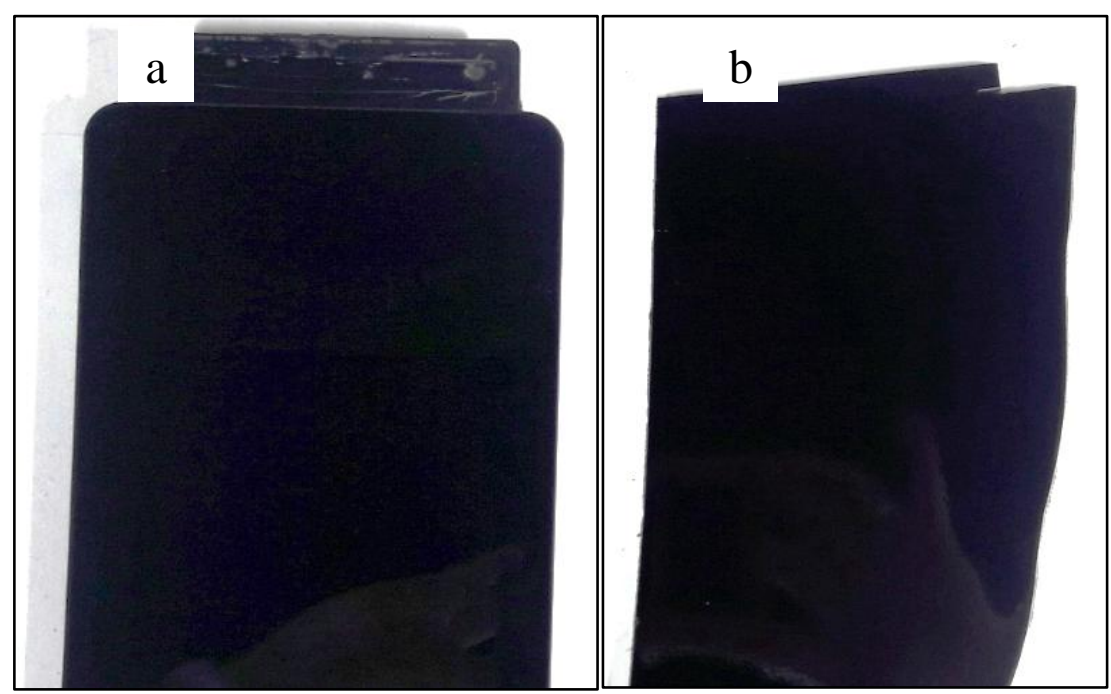

Figure 9: Image of a) one step production systems with polyurethane lacquer and

b) conventional paint system with acrylic paint after test 
Table 4: Gloss loss values after thermal aging test

\begin{tabular}{|l|l|}
\hline Paint System & Gloss Loss $\left.\mathbf{( 2 0}^{\mathbf{}}\right)$ \\
\hline Conventional & 3,5 \\
\hline One step & 3,9 \\
\hline
\end{tabular}

Visual images on Figure 9 and gloss loss values in Table 4 indicated that there is no detrimental difference among the two paint system after the thermal aging test. Hot to cold thermal cycle did not affect gloss level of the coatings on the surfaces.

\subsection{Orange Peeling Formation Behaviour}

Orange peeling formation was measured without any aging or any other treatment on the surfaces. The plates of two different systems were analysed with Wave Scan instrument and recorded in the Table 5 comparatively.

Table 5: Results of conventional painting process with acrylic paint and one step production cycle with PU systems by Wave Scan instrument

\begin{tabular}{|l|l|l|}
\hline & Conventional & One step \\
\hline LW & 7 & 1.1 \\
\hline SW & 4 & 3.1 \\
\hline DOI & 85.5 & 96.4 \\
\hline
\end{tabular}

$\mathrm{R}^{*}$ : Specular angle at which the light is reflected is 10.5

LW and SW results indicate that conventional painting system with solvent based acrylic paint shows much orange peeling behaviour than one step production cycle with PU. In addition, DOI value of one step production with PU is $12 \%$ higher than conventional system.

\section{CONCLUSION}

This study was conducted to compare and analyse the effect of one step production cycle on surface quality when compared with traditional production system. Sample plates were prepared by traditional painting process with acrylic solvent-based paint and one step production cycle 
with PU coating systems. Gloss loss is 1,2 times higher and Ra value which is defining mean of all deviations is $13 \%$ higher for the conventional system than one step system. This result indicates that conventional solvent based acrylic paint systems are not so much resistant to scratches made by car wash apparatus. Polyurethane systems are more resistant, and this result can be attributed to elongation of these materials. Thermal aging resistance regarding gloss loss is the same for both systems since gloss loss results were very close to each other. DOI value of the conventional system is $12 \%$ less than one step system showing that orange peeling formation affinity for conventional system is more than one step system. It is known that visual quality depends of many external factors for conventional system such as operator competency, paint shop conditions. Since one step production system is closed to external factors, robust control of painting process can be provided by one step production system. This robustness of the system contributes the surface quality of painted plates.

\section{ACKNOWLEDGMENTS}

We would like to thank to TOFAŞ Türk Otomobil Fabrikası A.Ş. and VOTTELER Lackfabrik $\mathrm{GmbH} \& \mathrm{Co}$. KG for their support and motivation. All tests were conducted at Tofaş Türk Otomobil Fabrikası A.Ş. R\&D Material Engineering Department Laboratory.

\section{REFERENCES}

[1] Mitzler J., Dykhuis M., Reuter S., Schelter D. (2014). One Surface, Three Effects. Kunststoffe International, 9, 41-44.

[2] Mitzler J., Dykhuis M., Moch t., Gerndorf R. (2014). An Affordable Alternative to Conventionally Painted Parts. Kunststoffe International, 10, 85-88.

[3] Kienzl W., Fischer M., Steinbichler G., Plinke S., Kralicek M. (2016). High Quality Interior Components at Low Unit Cost. Kunststoffe International, 12, 43-45.

[4] Hanson A. R. (2006). Measurement Good Practice Guide No.94. Teddington: Crown 